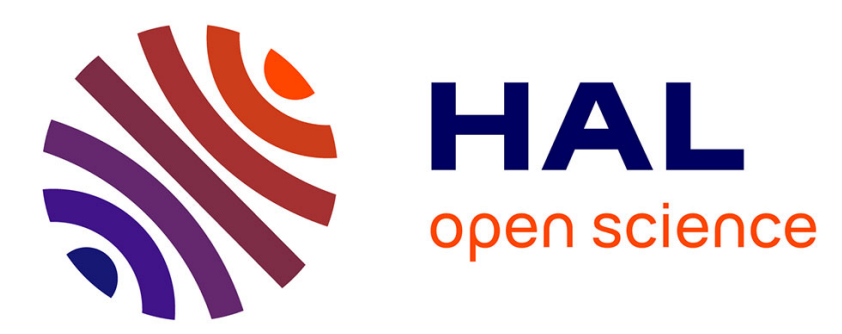

\title{
Random monoallelic expression of genes on autosomes: Parallels with X-chromosome inactivation
} Anne-Valerie Gendrel, Lucile Marion-Poll, Kimiko Katoh, Edith Heard

\section{To cite this version:}

Anne-Valerie Gendrel, Lucile Marion-Poll, Kimiko Katoh, Edith Heard. Random monoallelic expression of genes on autosomes: Parallels with X-chromosome inactivation. Seminars in Cell and Developmental Biology, 2016, 10.1016/j.semcdb.2016.04.007 . hal-01312980

\section{HAL Id: hal-01312980 \\ https://hal.sorbonne-universite.fr/hal-01312980}

Submitted on 9 May 2016

HAL is a multi-disciplinary open access archive for the deposit and dissemination of scientific research documents, whether they are published or not. The documents may come from teaching and research institutions in France or abroad, or from public or private research centers.
L'archive ouverte pluridisciplinaire HAL, est destinée au dépôt et à la diffusion de documents scientifiques de niveau recherche, publiés ou non, émanant des établissements d'enseignement et de recherche français ou étrangers, des laboratoires publics ou privés. 


\title{
Random monoallelic expression of genes on autosomes: Parallels with X- chromosome inactivation
}

\author{
Anne-Valerie Gendrel ${ }^{1,2 \star}$, Lucile Marion-Poll ${ }^{1,2 \star}$, Kimiko Katoh ${ }^{1,2 \star}$ and Edith Heard ${ }^{1,2}$ \\ 1. Institut Curie, PSL Research University, CNRS UMR3215, INSERM U934, Mammalian \\ Developmental Epigenetics group, F-75005 Paris, France.
}

2. Sorbonne Universités, UPMC Univ Paris 6, F-75005, Paris, France.

* These authors contributed equally to this work.

Corresponding authors: anne-valerie.gendrel@curie.fr; edith.heard@curie.fr

\begin{abstract}
Genes are generally expressed from their two alleles, except in some particular cases such as random inactivation of one of the two $X$ chromosomes in female mammals or imprinted genes which are expressed only from the maternal or the paternal allele. A lesser-known phenomenon is random monoallelic expression (RME) of autosomal genes, where genes can be stably expressed in a monoallelic manner, from either one of the parental alleles. Studies on autosomal RME face several challenges. First, RME that is based on epigenetic mechanisms has to be distinguished from biased expression of one allele caused by a DNA sequence polymorphism in a regulatory element. Second, RME should not be confused with transient monoallelic expression often observed in single cell analyses, and that often corresponds to dynamic bursting of expression. Thanks to analyses on clonal cell populations, the existence of RME in cultured cells is now well established. Future studies of RME in vivo will have to overcome tissue heterogeneity and certain technical limitations. Here, we discuss current knowledge on autosomal RME, as well as possible mechanisms controlling these expression patterns and potential implications for development and disease, drawing parallels with what is known for X-chromosome inactivation, a paradigm of random monoallelic expression.
\end{abstract}

\section{Introduction}

Diploid organisms possess two alleles of each gene in their genome, one inherited from each parent. In most cases, the two alleles are believed to be expressed at about the same time and at similar levels in cells. However, transcription being a highly stochastic and bursty process, differences in expression between two alleles can be observed for some genes at any given point in time when cells are analysed individually. These differences, which results in cell-to-cell variability, are dynamic throughout the cell cycle and masked when looking at a cell population. Genes can also be expressed either strictly or preferentially from either one of the two alleles in a stable and clonally heritable manner during mitosis. In this case, one of the alleles is either less active or in the most extreme case, completely silent, resulting respectively in biased or strict monoallelic expression. In this review we will 
mainly concentrate on mitotically stable random monoallelic expression (RME) but will touch on the possibly related phenomenon of dynamic and transient monoallelic expression that can result from transcriptional bursting [1, 2].

Allele-specific gene expression is most often associated with DNA sequence polymorphisms between alleles, either at the single nucleotide level for example within regulatory sequences, or for larger portions of the genome caused by copy-number variations, which, in both cases, may result in gene dosage imbalances [3]. However, monoallelic expression can also be based on differential gene activity that does not depend on DNA polymorphisms, but rather on differential epigenetic marking of the two alleles. There are three main classes of genes in mammalian genomes that display such epigenetically based monoallelic expression, without being due to differences in the underlying DNA sequence.

The most classic example concerns genes that are subject to random $\mathrm{X}$-chromosome inactivation $(X C l)$. Here, to ensure dosage compensation between $X X$ and $X Y$ cells, one of the two $X$ chromosomes is chosen for silencing during early development, and once established the inactive state is stably maintained throughout mitotic divisions, thanks to a combination of epigenetic marks including chromatin-associated proteins, histone post-translational modifications, DNA methylation of $\mathrm{CpG}$ islands as well as asynchronous replication [4]. Females are thus cellular mosaics for X-linked gene activity with cells expressing either the paternal or the maternal $X$ chromosome. A few genes can however escape from this process of $\mathrm{XCI}$, such as Jarid1c $(K d m 5 c)$ or Utx (Kdm6a), which escape in most cell types, and other genes that escape in a tissue or lineage-specific fashion, such as Atrx [5, 6], suggesting that a double dose of certain X-linked genes may be important for females in some cases [7]. It appears also that genes can escape $\mathrm{XCl}$ in a more stochastic or facultative manner in some cells but not others, indicating $\mathrm{XCl}$ is less stably maintained at some loci for as yet unknown reasons (Figure 1).

The other well-known example of monoallelic regulation concerns genes subject to genomic imprinting, which are expressed from a single allele in a parent-of-origin manner. Around a hundred loci in mammalian genomes, autosomal for the most part, are subject to parent-of-origin dependent expression. Differential marking of parental loci is laid down in the germ line and usually involves DNA methylation of an imprinting control region that influences in cis several genes located in clusters, in contrast to a full chromosome in $\mathrm{XCl}$. These expression patterns are maintained throughout mitosis and adult life, so that most cells express the same parental allele of a gene. Loss of imprinting can lead to several human disorders [8]. However, biallelic expression has been observed in specific tissues for some genes and could play a role in developmental plasticity [9].

A third class of monoallelic regulation concerns autosomal genes that are expressed in a random and clonal fashion, from either the paternal or maternal allele, as in $\mathrm{XCl}$ but unlike imprinted genes. This class traditionally includes members of large genes families, such as olfactory receptors, antigen receptors and protocadherins, which are usually expressed in a single and highly specialized cell type. One typical property of these families is that genes are clustered in large arrays at one or several locations on autosomes and their RME may act to specify cell identity and to enhance diversity within a cell population. Recent genome-wide studies have revealed that this group also includes some 
genes (around 2\%), which identity varies between tissues and that are scattered in singletons throughout the genome and which can be stably expressed from either one or the other allele, independently of polymorphisms in the DNA sequence [10-12]. As these data come from averages of millions of cells from clonal populations, the observed monoallelic expression cannot be attributable to transcriptional bursts. These genes belong to a wide range of gene ontology categories, from cell adhesion molecules to transcription factors and tend to be expressed in a lineage-specific manner. Interestingly, several "isolated" imprinted genes have also been described [13]. It was proposed that imprinted loci may even have initially arisen from RME genes that entailed a selective advantage and thus became fixed in their regulation through the evolution of a germ line imprint [14].

In contrast to imprinted and X-inactivated genes, all documented cases of RME genes on autosomes can be expressed monoallelically from either the paternal or the maternal allele but also biallelically from their two alleles, which may contribute to generating some level of diversity within a cell population (Figure 1). RME patterns can be highly stable after establishment and clonally inherited during mitosis, similarly to imprinting or $\mathrm{XCl}$. Whether such epigenetically heritable RME in fact arises from an initially more dynamic (non-clonal) situation is still very much an open question. This review will focus on this class of autosomal genes showing RME. We will describe here the repertoire of genes showing these expression patterns, the potential molecular mechanisms that may underlie this mode of regulation, highlighting the similarities and differences with $\mathrm{XCl}$. We will also address the role that RME may play during development and in disease, again drawing parallels with what is known for $\mathrm{XCl}$. For the classes of imprinted or $\mathrm{X}$ inactivated genes, we refer the reader to excellent reviews on the topic $[7,15]$ including in this issue.

\section{Identity and features of genes showing random monoallelic expression}

\section{1-1. Clonal cell population analysis}

Classical examples of autosomal RME are represented by large gene families of cell surface immune or sensory receptors and associated with the generation of diversity between cells. Immunoglobulin in $B$ lymphocytes and T-cell receptor genes in T lymphocytes were the first cases of RME on autosomes to be described and shown to display what was later named 'allelic exclusion'. Allelic exclusion of antigen receptors is associated with DNA rearrangement events that take place only in the B or T lineages on a single allele and which will inhibit any further rearrangement and expression of the second allele, ensuring that only a single antigen receptor will be produced [16]. The other class of genes described to show allelic exclusion is the olfactory receptor (OR) genes, which are found in large arrays on many autosomes and are expressed in olfactory neurons exclusively. Here again, the expression of one allele leads to the repression of the second allele and all remaining members of the family (more than 1000 genes in the mouse genome) through an unknown feedback mechanism, resulting in expression of only one receptor in each cell [17]. Following these findings, other gene families were reported to show RME, such as the vomeronasal receptor genes expressed in vomeronasal sensory neurons [18] and the protocadherin genes in Purkinje neurons [19]. In addition, a number of single genes were shown to display RME. These include various interleukin genes (II2, $I I 4, I I 5, I 110, I 13$ ) in T cells [20, 21]; Ly49 receptors in natural killer cells [22]; the TIr4 (Toll-like receptor 
4) in mouse B cells [23]; the $p 120$ catenin in mouse pre-B cells and human lymphoblastoid cell lines [24]; the GFAP (glial fibrillary acidic protein) gene in mouse cortical astrocytes [25]; Krt12 in mouse corneal epithelial stem cells [26]; three genes clustered in the $t$ complex locus on mouse chromosome 17 (Jsap1, Nubp2 and lgfals) in bone marrow stromal cells [27]; and more recently, the human FOXP2 gene in B lymphoblasts and T cells [28]. These genes tend to be expressed in highly specific lineages where the monoallelic expression pattern was detected. Furthermore, the majority of these aforementioned genes, whether members of gene families or singletons, appear to encode cell surface receptors for which monoallelic expression likely leads to increased cell diversity within a population and which may be advantageous in the context of the immune system or in neuronal diversity [29].

The advent of whole genome sequencing, which provided single nucleotide polymorphism (SNP) information and the use of new technologies, such as SNP-arrays and next-generation sequencing, led to the realisation that such RME genes might be more widespread than previously thought. The first genome-wide analysis of RME was a seminal study from the laboratory of Andrew Chess, where SNP-arrays were used to examine nuclear RNA rather than DNA in order to determine the extent of clonally-inherited RME in B lymphoblastoid cell lines across human autosomes [30]. With this analysis, the authors estimated that nearly $10 \%$ of about 4,000 autosomal genes analysed are subject to RME in at least one clonal population of cells. More recently, high-throughput RNA sequencing (RNA-seq) was also used to address the extent of RME in clones of mouse neural stem cells (NSCs) or neural progenitor cells (NPCs), derived either from the brain of hybrid animals [10] or from hybrid embryonic stem (ES) cell lines [11, 12]. Importantly, genes must be monoallelically expressed from one allele in some clones and from the other allele in some other clones to be considered as RME, in order to rule out the influence of DNA sequence polymorphisms. These analyses consistently revealed a lower albeit significant proportion of genes showing RME, in the range of $2.5-3 \%$ of all genes analysed. Importantly, the percentages estimated from RNA-seq analyses excluded the most lowly expressed genes $(\mathrm{RPKM}<1)$, for which monoallelic expression might simply result from preferential detection of a single allele due to poor transcription levels. The differences in the extent of autosomal RME found between the SNP-array and the RNA-seq studies could have resulted from technical differences for calling monoallelic expression, or the thresholds considered, or else they may reflect biological differences between the cell types used.

\section{1-2.Single cell analysis}

Recent efforts using single cell approaches suggest that RME may be more widespread than initially thought, at least during development. In a study employing RNA-seq on single blastomeres from preimplantation embryos obtained from crosses between polymorphic mouse strains, apparent monoallelic expression from only one allele was detected for $12-24 \%$ of genes on autosomes across all preimplantation stages analysed, considering technical allelic loss and only genes with moderate to high expression levels [1]. Similar proportions were found in single-cell RNA-seq analyses from mouse adult hepatocytes and fibroblasts [1], while an analysis on single human primary fibroblasts revealed 
that more than $75 \%$ of autosomal genes show skewed or monoallelic expression from a single allele and that genes expressing their two alleles are rare and tend to show high expression levels and long half-life in most cells [2]. However, these findings do not reflect mitotically heritable patterns of RME, but rather the stochasticity of gene expression within single cells and the fact that transcription can occur independently on each allele in bursts, with short or long pauses in between bursts [31] (Figure 1). The detection of only one allele at a given time, and in a single cell, appears to be a rather frequent scenario, particularly for poorly transcribed genes and/or those with a short half-life. This observation is illustrated with the case of the Nanog gene that was described to show stochastic monoallelic expression during mouse pre-implantation development and in ES cells, based on allele-specific single-cell RT-PCR and RNA FISH analysis [32]. Subsequent analyses revealed that the pattern observed corresponds to dynamic bursting of expression of Nanog [33, 34].The so-called dynamic RME identified through single cell RNA-seq analyses [35] is conceptually different from clonally inherited RME. The major concern with single-cell analysis is that stable RME in a heterogeneous population cannot be distinguished from transient monoallelic expression inherent to transcriptional bursting. Our review focuses in all subsequent sections on clonally inherited RME exclusively.

\section{1-3. Features of random monoallelically expressed genes}

Although in some cases, RME genes lie on the same autosome and in relatively close proximity, the choice of which allele is active or silent appears to occur independently for each gene [11,30]. This is unlike the inactive $\mathrm{X}$ chromosome, which involves silencing of almost all genes in cis. Furthermore, in contrast to the strictly monoallelic expression of imprinted and X-linked genes, an important feature of autosomal RME genes is that their monoallelic status varies between different cell types, and that in independent clonal populations, they can be either biallelically or monoallelically expressed from the maternal or the paternal allele, or even not expressed at all $[11,12,30]$. In clonal NPC lines, these patterns of expression, whether biallelic or monoallelic, have been found to be remarkably stable, and inherited during extensive cell passaging [11]. Using nascent RNA FISH, a high proportion of monoallelically expressing cells, together with biallelic cells, could be detected in vivo, likely reflecting the mono/biallelic expression pattern seen in the clonal cell lines analyses, however with different tissue-specificities for the various genes analysed [11] (Figure 1). Further investigations are however required to determine whether the monoallelic pattern observed in vivo is random, stable and clonally inherited. A likely scenario may be that the transient monoallelic expression of some genes during development can sometimes become locked in and perpetuated in a particular tissue or cell lineage (see Section 2 below).

The genome-wide studies revealed that many RME genes encode a variety of receptors, adhesion molecules, ion channels and cell signalling molecules all expressed at the cell surface and involved in cell to cell interactions. Gene ontology analysis also revealed a broad distribution among various categories [11, 12, 30]. RNA-seq studies in NPCs differentiated from mouse ES cells uncovered several genes encoding important transcription factors, such as for example Six 1 and three members of the Eya gene family [11] that are required for development of multiple organs, including the inner ear and the kidney, where they appear to play critical roles at different stages. Furthermore, a 
computational analysis using the histone modification signature associated with autosomal RME [36] showed that this signature is predominant among cell-type specific genes and is underrepresented among genes with housekeeping activity [37], suggesting also a link with lineage specificity. A potential role for autosomal RME during development is described in Section 3 below.

Importantly, recent studies have pointed to several RME genes that are associated with autosomal dominant disorders in humans (Table 1). For example, the Eya1 and Six 1 genes have been associated with the branchio-oto (BO) and branchio-oto-renal (BOR) syndromes [38]; other genes are linked to diseases such as Alzheimer's, schizophrenia, epilepsy, alcohol dependence and cancer [10, $11,30]$. In another study, it has been reported that RME genes, initially identified in human NSCs [39], show an overrepresentation of schizophrenia risk candidates identified by genome wide association studies and copy-number variations associated with both schizophrenia and autism [40]. The potential contribution of RME to diseases including neurodegenerative disorders is discussed in Section 4 below.

\section{Mechanisms underlying establishment and maintenance of monoallelic expression compared to $\mathrm{XCl}$}

The mechanisms by which RME of autosomal genes is established and those by which it is maintained, both remain open questions. Indeed, even in $\mathrm{XCl}$, the exact mechanism underlying monoallelic upregulation of the Xist gene on only one allele is far from being fully understood despite decades of research on the Xist regulatory network [41]. Several mechanisms, that could act in combination, have been proposed to ensure Xist monoallelic upregulation: these include feedback loops that involve cis- and/or trans-acting regulators; transient pairing and symmetry breaking; the involvement of a pre-existing poised state on one allele; switching between alternate chromatin conformation states at each allele, enabling differential opportunities to allow Xist upregulation [42]; or stochastic monoallelic/biallelic Xist upregulation and secondary selection against cells that make the wrong choice (i.e. no XCl or inactivation of both alleles) (reviewed in [43]). Related mechanisms might account for the regulation of RME genes on autosomes, although so far no loci have been dissected in as much detail as the $\mathrm{X}$-inactivation centre (Xic). Nonetheless, inspired by studies on Xist, various reports have drawn parallels between some RME loci and regulation of the Xic. Likewise, the molecular mechanisms involved in maintenance of the inactive state of the $X$ chromosome [4] could be explored in the context of RME loci (Figure 2). Here we detail some of the common and divergent properties between $\mathrm{XCl}$ and autosomal $\mathrm{RME}$.

\section{2-1.Establishment of random monoallelic expression}

Few studies have investigated RME during the time window in which it is established. Indeed, the initiation time window is not known for most autosomal RME genes. It is also not known whether initiation of RME is due to a deterministic process, or else a stochastic process. The inherently stochastic nature of transcription occurring independently on the two alleles may underlie occasional fixed monoallelic states. If transcription levels are very low even transiently during development or differentiation, the lowly expressed or silent state of one allele could somehow become locked in and 
perpetuated in cis, during subsequent cell divisions. Monoallelic expression could also be established because the two alleles pre-exist in a sort of metastable state, owing to their genomic, chromatin or nuclear environment. For example, limiting amounts of a transcription factor could contribute to the preferential expression of just one allele in some cells, a state that could get propagated during mitosis. Moreover, the local chromosome configuration of a given gene can influence its transcriptional status, leading for example to alternate chromatin folding states that might fluctuate during the cell cycle and predispose one or the other allele to be expressed [42]. The immediate genomic environment of a gene may also be important for the initiation of RME. For example repetitive sequences, such as the long interspersed nuclear elements 1 (LINE-1) family of transposon, are present at higher density in the flanking regions of the three classes of genes showing monoallelic expression $[44,45]$. Such repeats can attract repressive protein complexes and create an environment potentially prone to silencing in cis, not only of repeats but also of neighbouring genes. Inefficient activation of a gene in a repetitive environment could lead to monoallelic expression. Alternatively, initially biallelic activation of a gene could be rendered stably monoallelic, through cis-spreading of repeat-induced heterochromatin (Figure 2).

At the Xic locus, interchromosomal pairing between homologous alleles occurs concomitant to monoallelic Xist upregulation in the mouse [46, 47]. This has not been detected for the few RME candidates examined so far in NPCs [12], but this would need to be investigated at a critical time when monoallelic expression is established. Furthermore, long range interactions with heterologous regulatory sequences could be important. The monoallelic expression of the human FOXP2 gene was predicted to depend in cis on a regulatory sequence located $3 \mathrm{Mb}$ upstream of the gene [28], raising the possibility that establishment of RME can rely on long range interactions with cis-regulatory element(s) (Figure 2). Whether such enhancer elements function to enable fluctuating expression states as proposed for the Xist/Tsix locus in $\mathrm{XCl}$ [42], or whether this is an inefficient enhancer that leads to highly stochastic patterns remains to be found.

Another feature of the Xic and some imprinted loci is that non-coding RNAs (ncRNA) overlapping a locus or transcribed in its vicinity are involved in establishing monoallelic expression $[4,8]$. In XCl, the non-coding Tsix gene transcribed antisense to Xist is thought to mediate its repression and contribute to its RME in early differentiating ES cells [48]. As in $\mathrm{XCl}$, the presence of antisense transcription and/or of ncRNA acting locally in cis may trigger differential transcription between alleles in a stochastic manner, a state that could become fixed in some cells (Figure 2). It is not known yet if antisense transcription and/or nearby ncRNAs are associated with autosomal RME loci. However, a large intergenic ncRNA, called ASAR6 (for Asynchronous replication and autosomal RNA on chromosome 6) that shares a number of properties similar with Xist was recently described in humans $[49,50]$. The ASAR6 locus itself shows RME in immortalized cell lines and has been shown to be required in cis to orchestrate the asynchronous replication timing and silencing of monoallelically expressed genes located in the vicinity, even though the RNA does not coat the entire chromosome. Indeed, disruption of the ASAR6 locus delays replication timing of some genes along the chromosome, similar to observations made with Xist [51], and leads to biallelic expression of 
previously monoallelically expressed genes $[49,50]$. However, the molecular mechanisms underlying the monoallelic regulation of ASAR6 remain unknown, as for Xist.

At last, negative feedback loops where the active allele leads to silencing of the other allele could also lead to monoallelic expression (Figure 2), similar to what has been described in allelic exclusion of immunoglobulin and T-cell receptor genes. Here, a functional rearrangement on one of the two alleles will inhibit any further rearrangement of the second allele [16]. Likewise, for the OR genes, expression of a single OR gene is accomplished through a negative-feedback signal mediated by the OR coding sequence and triggered by expression of a single and functional $O R$ protein that will prevent activation of any additional alleles [17]. Whether similar mechanisms mediate the mitotically stable monoallelic expression of singleton RME genes in a clonal cell population, beyond highly specialized cell types such as lymphocytes and olfactory neurons, remain an open question.

\section{2-2. Maintenance of random monoallelic expression}

Another critical feature concerns the mechanisms underlying the faithful maintenance of the differential allelic expression across cell divisions (cf. Figure 2). RME of autosomal genes has been shown to be very stably maintained, once established, at least in NPCs where this could be tested upon long-term passaging and differentiation (for example into astrocytes) [11]. This suggests that similarly to $\mathrm{XCl}$ and genomic imprinting, epigenetic mechanisms may be at play to maintain these expression patterns. DNA methylation at $\mathrm{CpG}$ islands, as well as histone modifications such as $\mathrm{H} 3 \mathrm{~K} 27 \mathrm{me} 3$ and $\mathrm{H} 3 \mathrm{~K} 9 \mathrm{me} 2$ are found on the inactive alleles of $X$-inactivated genes [4, 52]. RME loci have also been shown to display specific epigenetic modifications. Analysis of the DNA methylation levels of the promoter regions of a few RME gene candidates by bisulfite-based analysis revealed that even if some RME genes exhibit methylation levels that are compatible with their RME profile ( $50 \%$ methylation when monoallelic and no methylation when biallelic), others do not [11, 12]. Chromatin immunoprecipitation followed by sequencing and SNP analysis on murine clonal NPCs revealed that active RME alleles are frequently associated with the $\mathrm{H} 3 \mathrm{~K} 4 \mathrm{me} 2 / 3$ mark, while the inactive allele is frequently associated with heterochromatic $\mathrm{H} 3 \mathrm{~K} 9 \mathrm{me} 3$ marks at promoter regions [12]. This is consistent with previous studies correlating such marks with active and silent states. In another study, the presence of both H3K27me3 and H3K36me3 marks was found across the bodies of many RME genes, suggesting that this may be a chromatin signature of autosomal RME in lymphoblasts, of both human and murine origin [36, 37]. The authors also proposed that this dual active/inactive chromatin mark signature could be used as a predictive tool to infer autosomal RME in mouse cells of lymphoid, mesenchymal, and neuroectodermal lineage [37]. Furthermore, this signature appears to remain unchanged between progenitor cells and their differentiated derivatives among different cell types, suggesting a potential role in maintenance of these expression patterns [37].

Asynchronous replication timing, whereby one allele replicates earlier than the other during $S$ phase, is also considered as an epigenetic characteristic and is a property shared by all classes of monoallelically expressed genes [53-55] (Figure 2). The entire inactive $X$ chromosome shifts to late replication timing compared to the active $X$ [54], indicating that the asynchrony is coordinated in cis along the entire chromosome. Late replication timing of the inactive $X$ is believed to contribute to the 
maintenance of the silenced state [56]. However, in the case of autosomal RME loci, the asynchronous replication is not always coordinated at the chromosome level, unlike previously thought [55] and moreover, many RME loci do not overlap with asynchronously replicating regions of the mouse genome [11, 30], indicating that this feature is not a bona-fide property of autosomal RME. It was also suggested that asynchronous replication could even precede monoallelic expression and as such may be involved in the initial choice of which allele to express or silence $[57,58]$. In any case, allele-specific genome wide analyses of replication timing before and after RME establishment are needed to draw more definitive conclusions.

Another possible mechanism for maintaining differential expression of two alleles of a given RME gene could be through differential nuclear location, either within nuclear compartments or transcriptional environments within the nucleus (Figure 2). Again, this is something that was previously proposed to occur in $\mathrm{XCl}$, where the inactive $\mathrm{X}$ chromosome is often found near the nucleolus or at the nuclear periphery [59], two subnuclear structures that are more associated with silent sequences. Nuclear organisation also plays a role in $\mathrm{OR}$ and immunoglobulin gene regulation [60,61]. In the case of autosomal RME, the analysis of a few candidates in NPCs by RNA/DNA FISH did not report any preferential positioning of the inactive allele with the nuclear periphery or near heterochromatic foci [12]. An interesting example concerns the GFAP gene, which shows RME in murine cortical astrocytes, and where the active and inactive alleles occupy distinct radial position within the nucleus, with the active alleles being preferentially more internal in the nucleus than the inactive ones [25]. This may serve as a mechanism to stabilize and maintain the transcriptional states. However, functional studies are needed to assess whether this change in nuclear position is a cause or a consequence of the differentially silenced/active states, just as for all the above potential mechanisms.

\section{Potential roles of random monoallelic expression}

In this section, we will attempt to draw parallels between what is known about the role of $\mathrm{XCl}$ with autosomal RME.

\section{3-1. X-chromosome inactivation}

In mammalian female embryos, the inability to silence one X-chromosome is rapidly lethal [62]. During early mouse development, the two $\mathrm{X}$ chromosomes are transiently found in an active state. The presence of two active Xs has been shown to stabilise the naïve pluripotent state and to inhibit the onset of differentiation using ES cells [63]. This differentiation block is released once XX ES cells have undergone $\mathrm{XCl}$, illustrating the tight relationship between dosage compensation and development and in this case a vital requirement for monoallelic expression of $\mathrm{X}$-linked genes.

In eutherian mammals, $\mathrm{XCl}$ is generally random in somatic tissues, while in marsupials, imprinted inactivation of the paternal $X$ chromosome is found in all tissues [4]. The phylogeny of mammals and their respective silencing mechanisms regarding $\mathrm{X}$-chromosome suggest that imprinted $\mathrm{XCl}$ appeared first and then evolved to random $\mathrm{XCl}$ in some species [41]. Randomness could confer an evolutionary advantage over imprinting for several reasons. First, a deleterious mutation would not affect every cell of the organism, and cells expressing the normal copy could be selected or compensate for the 
detrimental effects, at least in part. Second, it can be advantageous to have two different versions of a given gene. For example, the X-linked gene G6PD encodes for the Glucose-6-phosphate dehydrogenase, which notably protects red blood cells from oxidative damage. On the one hand, the G6PD A- variant can lead to haemolytic anaemia but on the other hand this allele has been associated with resistance to malaria. Overall, in heterozygous females, the expression of both $A+$ and $A$ - alleles provides resistance to malaria without the haemolytic anaemia disease [64, 65].

Another interesting example is the colour vision in platyrrhine monkeys. A single locus on the Xchromosome can encode two different versions of a photopigment gene, with different wavelength sensitivities. Consequently, heterozygous females have a trichromatic vision whereas males and homozygous females can only detect two colours [66]. Finally and more generally, as suggested by Wu and colleagues [67], $\mathrm{XCl}$ mosaicism could expand the dynamic range of potential stimulusresponse of a neuronal assembly. Thus, random XCl could play a critical role in brain function, a likely scenario given the large number of $\mathrm{X}$-linked genes that are expressed in the brain.

\section{3-2. Autosomal random monoallelic expression}

As mentioned earlier, the immune and OR gene families display RME and this property may have been selected for, in order to enhance the specificity of the response, either to antigens or to sensory stimuli. Interestingly, the specific expression of ORs is known to play a role in axon guidance of primary sensory neurons during brain development and establishment of the topographic sensory map [68].

The variable exons of the protocadherin-alpha gene cluster were also identified as showing RME in the brain, at least in Purkinje cells [19]. Thanks to this process, these neurons express various versions of this homophilic cell-adhesion protein in the cerebellum. Protocadherins are implicated in self-recognition processes [69], so the individual diversity induced by RME of protocadherin-alpha could allow neurons to avoid making self-contacts, which could be essential for proper development and function of brain networks.

Besides these gene families, many individual genes have the potential to be expressed in a random monoallelic manner as discussed above, but unlike immune and sensory receptors, they may also display biallelic expression or no expression within a cell population. These genes belong to a wide range of functional categories, with an overrepresentation of genes encoding cell-surface receptors, as well as genes involved in organ development such as transcription factors [19]. The potential in vivo relevance of the RME pattern of these genes remains to be uncovered. However, relying on our knowledge of X-linked monoallelic expression and on the function of some well-known genes at stake, we can speculate on the role autosomal RME may play.

The main role of $\mathrm{XCl}$ is thought to ensure adequate gene dosage of $\mathrm{X}$-linked genes relative to autosomes and also between the sexes. Autosomal RME genes appear to show overall higher expression levels when they are expressed biallelically, than when they are expressed from a single allele [11]. Moreover, genes can also show biased expression towards one or the other allele, in different proportions, suggesting that RME of autosomal genes has the potential to fine-tune gene dosage. 
Some RME genes encode key developmental factors and their precise protein levels, through regulation of RME, might be required to ensure lineage-commitment and/or cell fate specification. In addition to this, RME profiles are often highly stage- and tissue-specific and there seems to be a general increase in monoallelic expression during differentiation [12]. An interesting example is the Eya1 (EYA transcriptional coactivator and phosphatase 1) gene, which was shown to be monoallelic in NPCs [11]. Although Eya1 may not play a critical role in NPCs, the reported allelic expression pattern in NPCs is a proof-of-principle that Eya1 can be monoallelically expressed. Eya1 plays a critical role in inner ear development [70], as its expression is necessary to induce hair cell fate in the cochlea and required for the proper expression pattern of other transcription factors in subsequent neurogenesis. Loss of Eya1 leads to an arrest of otic development [71]. Interestingly, this gene is extremely dosagesensitive [72, 73], as both heterozygous missense mutations and duplication cause hearing loss in human [74, 75]. EYA1 mutations are known to cause autosomal dominant BOR and BO syndromes with incomplete penetrance. Thus, if genes such as EYA1 are expressed in a random monoallelic fashion, this could have critical implications during development for cell fate specification and in the context of heterozygous mutations, thus contributing to autosomal dominant disorders. Given that the RME state of these genes is mitotically heritable in clonal NPCs, this implies that a transient RME state during development may sometimes become epigenetically stable.

Intriguingly, we believe that RME could have a substantial impact on brain function in particular. The potential roles of genes encoding cell-adhesion molecules, such as protocadherin-alpha in generating neuronal diversity and allowing self-recognition of individual neurons, were already mentioned. In addition, other genes with important functions in the brain have been found to be RME. These include transcription factors such as FOXP2 [28], ion channels (including numerous potassium channels), as well as activity-regulated genes such as Arc (Activity-regulated cytoskeleton-associated protein) [11]. Hence, RME may be critical not only in influencing brain development but also for neuronal excitability and plasticity.

Random $\mathrm{XCl}$ results in cellular mosaicism for expression of the paternal and maternal $\mathrm{X}$-chromosome in females. Similarly, autosomal RME could lead to somatic mosaicism in both $X X$ and $X Y$ individuals. Furthermore, autosomal RME appears to be highly cell-type and tissue-specific for different genes, and it may occur to variable extents unlike $\mathrm{XCl}$, which occurs in all cells. Thus, RME could produce a remarkable cellular diversity, virtually infinite if we consider all the possible expression states and tissue distributions (Figure 3), with potential advantages for the organism.

\section{Association of random monoallelic expression with human diseases}

In this section, we will discuss the implications of RME of some X-linked and autosomal genes in human genetic disorders.

\section{4-1. X-linked disorders}

The X-chromosome carries over 1000 protein-coding genes and numerous disorders associated with $X$-linked genes have been studied intensively, due to the fact that any phenotype associated with an alteration or mutation of a gene on the $X$ is immediately manifested in $X Y$ males. Some of the best 
known X-linked diseases include the fragile $\mathrm{X}$ syndrome (FMR1 gene), Duchenne muscular dystrophy $(D M D)$, Rett syndrome (MECP2) and red-green vision deficiency (OPN1LW and OPN1MW). In general males are more severely affected because of their hemizygous state. For example, F8 or F9 gene mutations cause haemophilia in males, while heterozygous females can often be completely asymptomatic [76]. This is thought to be due to secondary selection during haematopoiesis that eliminates those cells where the inactive $X$ carries the wild type allele. On the other hand, even if a female is heterozygous for a mutation and has one functional copy of a gene, there can be a strong disease phenotype from the cells where the wild type allele is inactivated, such as in cranio-frontonasal syndrome (EBFN1 mutation) [77].

$M E C P 2$ that encodes the "methyl-CpG binding protein 2", particularly abundant in the brain [78], is another example - as males with a mutant MECP2 gene die at an early age, while females survive but develop Rett syndrome, a severe progressive neurological disorder [79], affecting communicative and motor abilities with profound cognitive impairment [80]. MECP2 is one of the X-linked genes where dosage (i.e. bialleic as opposed to monoallelic expression) has been shown to be critical in a diseasecontext. Indeed, MECP2 duplications also cause severe mental retardation in males [81], and mild to severe mental retardation in females [82]. As either loss or gain of function of the gene leads to neurological diseases, this highlights that the appropriate regulation of MECP2 dosage is essential for proper neural development and function.

The situation for individuals with extra $X$ chromosomes is also of interest when considering $X$-linked dosage. Such individuals are usually viable because every diploid cell retains only one active $X$, with all the others being inactivated. These chromosomal conditions are not rare, with about 1:600 males having Klinefelter's syndrome (XXY; one extra $X)$ and about 1:1000 females having triple $X$ syndrome $(X X X)$. An extra $X$ chromosome is associated with a taller stature, an increased risk of learning disabilities and sterility in males, which probably results from increased expression levels of genes that escape XCI.

The absence of one $X$ chromosome leads to no obvious phenotypes in female mice. However in humans, $X O$ individuals have Turner syndrome. Ninety-nine percent of $X$ monosomies are thought to abort spontaneously [83], suggesting that two copies of some X-linked genes that escape $\mathrm{XCl}$ are essential, including those in the pseudoautosomal regions (PAR1, PAR2 and PAR3 [84]). Since both males and females have two functional and equivalent copies of all PAR genes, there is no requirement for dosage compensation of these genes, however biallelic expression of some genes might be absolutely required in both sexes. For example, haploinsufficiency of the SHOX gene in the PAR1 region leads to a disorder called Leri-Weill dyschondrosteosis [85]. Moreover, a double dose could be also required for constitutive or facultative escapees located outside the PAR regions, such as the brain-specific NLGN4 gene, which is associated with autism [86].

Thus, the dosage regulation requirements for genes on the $X$ are highly complex - with a need to achieve monoallelic expression of most genes by $\mathrm{XCl}$, as well as a requirement for biallelic expression of some genes, that can vary during development and between tissues, somewhat like autosomal RME. 


\section{4-2. Autosomal random monoallelic expression and human disorders}

Few studies have explored RME of autosomal genes in vivo to date [1, 11, 30, 87]. Most studies have focused on clonal cell lines in vitro due to technical limitations [35]. Thus, the extent and role of RME in vivo is still an open question. However, a significant number of RME genes are now known to be linked to various diseases, suggesting that autosomal RME has a strong disease potential.

Correct dosage of many of the autosomal RME genes identified may in fact be essential. Two examples of genes for which protein dosage is critical in vivo and that have been reported to show RME in vitro [11, 12, 30], are APP (amyloid beta precursor protein) and SNCA (alpha-synuclein), implicated respectively in Alzheimer's [88] and Parkinson's diseases [89]. Whether these genes show monoallelic expression in vivo in the relevant brain regions is completely unexplored, but this could have important implications. In both cases, excess protein levels are known to be detrimental, leading to formation of amyloid plaques in the case of APP in Alzheimer's disease, and Lewy bodies in the case of SNCA and Parkinson's disease, as shown using transgenic mouse models. Therefore, if such genes are frequently monoallelic in the brain, epigenetic alterations, for example during aging [90], might lead to a dysregulation of RME mechanisms, and an increase of gene dosage which could potentially trigger the disease. RME mechanisms could be used as therapeutic targets to decrease the expression of such loci in a pathological context.

Another important consideration for autosomal RME genes is that, given the potentially mosaic expression patterns, if a gene were to be mutated on one allele, some cells could then express only the mutant allele. This is similar to the situation for $\mathrm{X}$-linked heterozygous mutations in females where some cells are functionally nullisomic. However, if there is a secondary selection against these cells such as for the X-linked mutations on F8-F9 genes, then monoallelic cells could always express the functional allele, thus alleviating the phenotype in a heterozygous context. If not, mutations on autosomal RME genes associated with diseases could show phenotypes in a heterozygous context. This is indeed the case (see Table 1). For example, both Eya1 and Six1 show stable RME in mouse NPCs and monoallelic expression of Eya1 has been observed in vivo during cochlear development in the mouse [11]. Heterozygous mutations in the EYA1 and $S I X 1$ genes are the main causes of BOR syndrome, an autosomal dominant disorder characterized by craniofacial abnormalities, hearing loss and kidney deficiency, which accounts for approximately $2 \%$ of childhood deafness [38]. It is intriguing that several Eya factors as well as Six1, work together, in the same complexes and also display RME, even though they are not located on the same chromosome. The SIX1 protein interacts with EYA1 to form a bipartite transcription factor essential for mammalian development. Loss of function of this complex causes BOR syndrome, whereas re-expression of SIX1 or EYA promotes metastasis. The EYA1-SIX1 complex is involved in inner ear organogenesis and also plays a critical role in the development of the metanephric mesenchyme during kidney development [38]. While Eya1 homozygous mutant mice lack ears and kidneys, heterozygous mutant mice exhibit a conductive hearing loss and renal abnormalities reminiscent of the BOR syndrome [91]. These observations suggest that RME of EYA1 and $S I X 1$ could play a role in BOR syndrome aetiology, a promising avenue for further investigations. More generally, transient monoallelic expression of the Eya and Six 
genes may be a means of enabling the fine tuning of the dosage and stoichiometry of EYA1-SIX1 transcription factors complexes, which may in turn be critical to allow precise doses of signals that enable appropriate morphogenesis.

Finally, we had discussed above that X-linked genes are particularly expressed in the brain and linked to neurological disorders. As for RME genes, APP and SNCA were mentioned, but many other genes appear to be related to brain function [11]. Therefore, besides neurodegenerative diseases, RME has also the potential to be implicated in neurological diseases such as autism, schizophrenia [40,92] or developmental speech and language disorders [28].

\section{Conclusion}

The existence of autosomal genes displaying RME that is mitotically stable has been well-established in clonal cell populations in vitro. Stable RME is found for genes with a wide range of functions, including a number known to play critical roles during development and in cell identity. On the one hand, RME could be advantageous, as it has the potential to generate a remarkable level of cell diversity by exposing different alleles and it also represents a mechanism for fine-tuning gene dosage if necessary, particularly during development. On the other hand, RME also comes with disadvantages, as expression of a single allele can predispose the organism to loss of function in the context of heterozygous mutations or epimutations, thereby contributing to disease. The extent of RME in vivo and its biological function(s) are still somewhat debated, as there may be a substantial degree of variability between individuals, as well as between cells and tissue type within an individual. Future studies will have to overcome tissue heterogeneity and current technical limitations. In particular, the clonal stability of RME in vivo is a critical question to address and will have to be disentangled from transient monoallelic expression which results from transcriptional bursting. In fact, stable RME may be an occasional but not systematic outcome of transient monoallelic expression. Given the major implications that stable RME might have in disease, defining the mechanisms underlying the establishment and maintenance of RME patterns represents an important challenge. Fortunately, the last half-century of research on random $\mathrm{XCl}$ should provide a sound basis of concepts and tools with which to tackle random monoallelic expression of autosomal loci.

\section{Acknowledgements}

We would like to thank Rickard Sandberg for helpful comments of the manuscript. Funding in the Heard lab is from EU project SYBOSS, EU project MODHEP, La Ligue (Equipe Labellisée), the Labex DEEP (ANR-11-LBX-0044) which is part of the Idex PSL (ANR-10-IDEX-0001-02 PSL), and for the research directly relevant to this topic, from an ERC advanced investigator grant "EpigenetiX", EU EpiGeneSys Network, and currently from BIOGEN Idec.

\section{References}


[1] Q. Deng, D. Ramskold, B. Reinius, R. Sandberg, Single-cell RNA-seq reveals dynamic, random monoallelic gene expression in mammalian cells, Science 343(6167) (2014) 193-6.

[2] C. Borel, P.G. Ferreira, F. Santoni, O. Delaneau, A. Fort, K.Y. Popadin, M. Garieri, E. Falconnet, P. Ribaux, M. Guipponi, I. Padioleau, P. Carninci, E.T. Dermitzakis, S.E. Antonarakis, Biased allelic expression in human primary fibroblast single cells, Am J Hum Genet 96(1) (2015) 70-80.

[3] H.T. Bjornsson, T.J. Albert, C.M. Ladd-Acosta, R.D. Green, M.A. Rongione, C.M. Middle, R.A. Irizarry, K.W. Broman, A.P. Feinberg, SNP-specific array-based allele-specific expression analysis, Genome Res 18(5) (2008) 771-9.

[4] A.V. Gendrel, E. Heard, Noncoding RNAs and Epigenetic Mechanisms During X-Chromosome Inactivation, Annual review of cell and developmental biology 30 (2014) 561-80.

[5] D. Garrick, J.A. Sharpe, R. Arkell, L. Dobbie, A.J. Smith, W.G. Wood, D.R. Higgs, R.J. Gibbons, Loss of Atrx affects trophoblast development and the pattern of $\mathrm{X}$-inactivation in extraembryonic tissues, PLoS Genet 2(4) (2006) e58.

[6] C. Patrat, I. Okamoto, P. Diabangouaya, V. Vialon, P. Le Baccon, J. Chow, E. Heard, Dynamic changes in paternal X-chromosome activity during imprinted X-chromosome inactivation in mice, Proc Natl Acad Sci U S A 106(13) (2009) 5198-203.

[7] S.B. Peeters, A.M. Cotton, C.J. Brown, Variable escape from X-chromosome inactivation: identifying factors that tip the scales towards expression, Bioessays 36(8) (2014) 746-56.

[8] R.N. Plasschaert, M.S. Bartolomei, Genomic imprinting in development, growth, behavior and stem cells, Development 141(9) (2014) 1805-13.

[9] S.R. Ferron, M. Charalambous, E. Radford, K. McEwen, H. Wildner, E. Hind, J.M. MoranteRedolat, J. Laborda, F. Guillemot, S.R. Bauer, I. Farinas, A.C. Ferguson-Smith, Postnatal loss of Dlk1 imprinting in stem cells and niche astrocytes regulates neurogenesis, Nature 475(7356) (2011) 381-5.

[10] S.M. Li, Z. Valo, J. Wang, H. Gao, C.W. Bowers, J. Singer-Sam, Transcriptome-wide survey of mouse CNS-derived cells reveals monoallelic expression within novel gene families, PLoS One 7(2) (2012) e31751.

[11] A.V. Gendrel, M. Attia, C.J. Chen, P. Diabangouaya, N. Servant, E. Barillot, E. Heard, Developmental dynamics and disease potential of random monoallelic gene expression, Dev Cell 28(4) (2014) 366-80.

[12] M.A. Eckersley-Maslin, D. Thybert, J.H. Bergmann, J.C. Marioni, P. Flicek, D.L. Spector, Random monoallelic gene expression increases upon embryonic stem cell differentiation, Dev Cell 28(4) (2014) 351-65.

[13] C.A. Edwards, A.C. Ferguson-Smith, Mechanisms regulating imprinted genes in clusters, Curr Opin Cell Biol 19(3) (2007) 281-9.

[14] R. Ohlsson, A. Paldi, J.A. Graves, Did genomic imprinting and X chromosome inactivation arise from stochastic expression?, Trends Genet 17(3) (2001) 136-41.

[15] A.C. Ferguson-Smith, Genomic imprinting: the emergence of an epigenetic paradigm, Nat Rev Genet 12(8) (2011) 565-75.

[16] H. Cedar, Y. Bergman, Choreography of Ig allelic exclusion, Current opinion in immunology 20(3) (2008) 308-17.

[17] K. Monahan, S. Lomvardas, Monoallelic Expression of Olfactory Receptors, Annual review of cell and developmental biology 31 (2015) 721-40.

[18] I. Rodriguez, P. Feinstein, P. Mombaerts, Variable patterns of axonal projections of sensory neurons in the mouse vomeronasal system, Cell 97(2) (1999) 199-208.

[19] S. Esumi, N. Kakazu, Y. Taguchi, T. Hirayama, A. Sasaki, T. Hirabayashi, T. Koide, T. Kitsukawa, S. Hamada, T. Yagi, Monoallelic yet combinatorial expression of variable exons of the protocadherinalpha gene cluster in single neurons, Nat Genet 37(2) (2005) 171-6.

[20] G.A. Hollander, S. Zuklys, C. Morel, E. Mizoguchi, K. Mobisson, S. Simpson, C. Terhorst, W. Wishart, D.E. Golan, A.K. Bhan, S.J. Burakoff, Monoallelic expression of the interleukin-2 locus, Science 279(5359) (1998) 2118-21.

[21] B.L. Kelly, R.M. Locksley, Coordinate regulation of the IL-4, IL-13, and IL-5 cytokine cluster in Th2 clones revealed by allelic expression patterns, J Immunol 165(6) (2000) 2982-6.

[22] W. Held, J. Roland, D.H. Raulet, Allelic exclusion of Ly49-family genes encoding class I MHCspecific receptors on NK cells, Nature 376(6538) (1995) 355-8.

[23] J.P. Pereira, R. Girard, R. Chaby, A. Cumano, P. Vieira, Monoallelic expression of the murine gene encoding Toll-like receptor 4, Nature immunology 4(5) (2003) 464-70.

[24] A.A. Gimelbrant, A.W. Ensminger, P. Qi, J. Zucker, A. Chess, Monoallelic expression and asynchronous replication of p120 catenin in mouse and human cells, J Biol Chem 280(2) (2005) 13549. 
[25] T. Takizawa, P.R. Gudla, L. Guo, S. Lockett, T. Misteli, Allele-specific nuclear positioning of the monoallelically expressed astrocyte marker GFAP, Genes Dev 22(4) (2008) 489-98.

[26] Y. Hayashi, M.K. Call, C.Y. Liu, M. Hayashi, G. Babcock, Y. Ohashi, W.W. Kao, Monoallelic expression of Krt12 gene during corneal-type epithelium differentiation of limbal stem cells, Investigative ophthalmology \& visual science 51(9) (2010) 4562-8.

[27] Y. Sano, T. Shimada, H. Nakashima, R.H. Nicholson, J.F. Eliason, T.A. Kocarek, M.S. Ko, Random monoallelic expression of three genes clustered within $60 \mathrm{~kb}$ of mouse t complex genomic DNA, Genome Res 11(11) (2001) 1833-41.

[28] A.A. Adegbola, G.F. Cox, E.M. Bradshaw, D.A. Hafler, A. Gimelbrant, A. Chess, Monoallelic expression of the human FOXP2 speech gene, Proc Natl Acad Sci U S A 112(22) (2015) 6848-54.

[29] A. Chess, Mechanisms and consequences of widespread random monoallelic expression, Nat Rev Genet 13(6) (2012) 421-8.

[30] A. Gimelbrant, J.N. Hutchinson, B.R. Thompson, A. Chess, Widespread monoallelic expression on human autosomes, Science 318(5853) (2007) 1136-40.

[31] A. Raj, A. van Oudenaarden, Nature, nurture, or chance: stochastic gene expression and its consequences, Cell 135(2) (2008) 216-26.

[32] Y. Miyanari, M.E. Torres-Padilla, Control of ground-state pluripotency by allelic regulation of Nanog, Nature 483(7390) (2012) 470-3.

[33] D.A. Faddah, H. Wang, A.W. Cheng, Y. Katz, Y. Buganim, R. Jaenisch, Single-cell analysis reveals that expression of nanog is biallelic and equally variable as that of other pluripotency factors in mouse ESCs, Cell Stem Cell 13(1) (2013) 23-9.

[34] A. Filipczyk, K. Gkatzis, J. Fu, P.S. Hoppe, H. Lickert, K. Anastassiadis, T. Schroeder, Biallelic expression of nanog protein in mouse embryonic stem cells, Cell Stem Cell 13(1) (2013) 12-3.

[35] B. Reinius, R. Sandberg, Random monoallelic expression of autosomal genes: stochastic transcription and allele-level regulation, Nat Rev Genet 16(11) (2015) 653-64.

[36] A. Nag, V. Savova, H.L. Fung, A. Miron, G.C. Yuan, K. Zhang, A.A. Gimelbrant, Chromatin signature of widespread monoallelic expression, eLife 2 (2013) e01256.

[37] A. Nag, S. Vigneau, V. Savova, L.M. Zwemer, A.A. Gimelbrant, Chromatin Signature Identifies Monoallelic Gene Expression Across Mammalian Cell Types, G3 (Bethesda) 5(8) (2015) 1713-20.

[38] P.X. Xu, The EYA-SO/SIX complex in development and disease, Pediatr Nephrol (2012).

[39] A.R. Jeffries, L.W. Perfect, J. Ledderose, L.C. Schalkwyk, N.J. Bray, J. Mill, J. Price, Stochastic choice of allelic expression in human neural stem cells, Stem Cells 30(9) (2012) 1938-47.

[40] A.R. Jeffries, D.A. Collier, E. Vassos, S. Curran, C.M. Ogilvie, J. Price, Random or stochastic monoallelic expressed genes are enriched for neurodevelopmental disorder candidate genes, PLoS One 8(12) (2013) e85093.

[41] E.G. Schulz, E. Heard, Role and control of X chromosome dosage in mammalian development, Curr Opin Genet Dev 23(2) (2013) 109-15.

[42] L. Giorgetti, R. Galupa, E.P. Nora, T. Piolot, F. Lam, J. Dekker, G. Tiana, E. Heard, Predictive polymer modeling reveals coupled fluctuations in chromosome conformation and transcription, Cell 157(4) (2014) 950-63.

[43] S. Augui, E.P. Nora, E. Heard, Regulation of X-chromosome inactivation by the X-inactivation centre, Nat Rev Genet 12(6) (2011) 429-42.

[44] E. Allen, S. Horvath, F. Tong, P. Kraft, E. Spiteri, A.D. Riggs, Y. Marahrens, High concentrations of long interspersed nuclear element sequence distinguish monoallelically expressed genes, Proc Natl Acad Sci U S A 100(17) (2003) 9940-5.

[45] J.A. Bailey, L. Carrel, A. Chakravarti, E.E. Eichler, Molecular evidence for a relationship between LINE-1 elements and $\mathrm{X}$ chromosome inactivation: the Lyon repeat hypothesis, Proc Natl Acad Sci U S A 97(12) (2000) 6634-9.

[46] N. Xu, C.L. Tsai, J.T. Lee, Transient homologous chromosome pairing marks the onset of $X$ inactivation, Science 311(5764) (2006) 1149-52.

[47] S. Augui, G.J. Filion, S. Huart, E. Nora, M. Guggiari, M. Maresca, A.F. Stewart, E. Heard, Sensing $X$ chromosome pairs before $X$ inactivation via a novel X-pairing region of the Xic, Science $318(5856)$ (2007) 1632-6.

[48] J.T. Lee, N. Lu, Targeted mutagenesis of Tsix leads to nonrandom X inactivation, Cell 99(1) (1999) 47-57.

[49] E.P. Stoffregen, N. Donley, D. Stauffer, L. Smith, M.J. Thayer, An autosomal locus that controls chromosome-wide replication timing and mono-allelic expression, Hum Mol Genet 20(12) (2011) 236678.

[50] N. Donley, E.P. Stoffregen, L. Smith, C. Montagna, M.J. Thayer, Asynchronous replication, monoallelic expression, and long range Cis-effects of ASAR6, PLoS Genet 9(4) (2013) e1003423. 
[51] S.V. Diaz-Perez, D.O. Ferguson, C. Wang, G. Csankovszki, S.C. Tsai, D. Dutta, V. Perez, S. Kim, C.D. Eller, J. Salstrom, Y. Ouyang, M.A. Teitell, B. Kaltenboeck, A. Chess, S. Huang, Y. Marahrens, A deletion at the mouse Xist gene exposes trans-effects that alter the heterochromatin of the inactive $X$ chromosome and the replication time and DNA stability of both X chromosomes, Genetics 174(3) (2006) 1115-33.

[52] D.P. Barlow, M.S. Bartolomei, Genomic imprinting in mammals, Cold Spring Harbor perspectives in biology 6(2) (2014).

[53] D. Kitsberg, S. Selig, M. Brandeis, I. Simon, I. Keshet, D.J. Driscoll, R.D. Nicholls, H. Cedar, Allele-specific replication timing of imprinted gene regions, Nature 364(6436) (1993) 459-63.

[54] N. Takagi, O. Sugawara, M. Sasaki, Regional and temporal changes in the pattern of Xchromosome replication during the early post-implantation development of the female mouse, Chromosoma 85(2) (1982) 275-86.

[55] N. Singh, F.A. Ebrahimi, A.A. Gimelbrant, A.W. Ensminger, M.R. Tackett, P. Qi, J. Gribnau, A. Chess, Coordination of the random asynchronous replication of autosomal loci, Nat Genet 33(3) (2003) 339-41.

[56] E. Heard, C.M. Disteche, Dosage compensation in mammals: fine-tuning the expression of the $X$ chromosome, Genes Dev 20(14) (2006) 1848-67.

[57] M. Farago, C. Rosenbluh, M. Tevlin, S. Fraenkel, S. Schlesinger, H. Masika, M. Gouzman, G. Teng, D. Schatz, Y. Rais, J.H. Hanna, A. Mildner, S. Jung, G. Mostoslavsky, H. Cedar, Y. Bergman, Clonal allelic predetermination of immunoglobulin-kappa rearrangement, Nature 490(7421) (2012) 561-5.

[58] I. Simon, T. Tenzen, B.E. Reubinoff, D. Hillman, J.R. McCarrey, H. Cedar, Asynchronous replication of imprinted genes is established in the gametes and maintained during development, Nature 401(6756) (1999) 929-32.

[59] L.F. Zhang, K.D. Huynh, J.T. Lee, Perinucleolar targeting of the inactive $X$ during $S$ phase: evidence for a role in the maintenance of silencing, Cell 129(4) (2007) 693-706.

[60] E.J. Clowney, M.A. LeGros, C.P. Mosley, F.G. Clowney, E.C. Markenskoff-Papadimitriou, M. Myllys, G. Barnea, C.A. Larabell, S. Lomvardas, Nuclear aggregation of olfactory receptor genes governs their monogenic expression, Cell 151(4) (2012) 724-37.

[61] S.T. Kosak, J.A. Skok, K.L. Medina, R. Riblet, M.M. Le Beau, A.G. Fisher, H. Singh, Subnuclear compartmentalization of immunoglobulin loci during lymphocyte development, Science 296(5565) (2002) 158-62.

[62] Y. Marahrens, B. Panning, J. Dausman, W. Strauss, R. Jaenisch, Xist-deficient mice are defective in dosage compensation but not spermatogenesis, Genes Dev 11(2) (1997) 156-66.

[63] E.G. Schulz, J. Meisig, T. Nakamura, I. Okamoto, A. Sieber, C. Picard, M. Borensztein, M. Saitou, N. Bluthgen, E. Heard, The Two Active X Chromosomes in Female ESCs Block Exit from the Pluripotent State by Modulating the ESC Signaling Network, Cell Stem Cell 14(2) (2014) 203-16.

[64] C. Ruwende, S.C. Khoo, R.W. Snow, S.N. Yates, D. Kwiatkowski, S. Gupta, P. Warn, C.E. Allsopp, S.C. Gilbert, N. Peschu, et al., Natural selection of hemi- and heterozygotes for G6PD deficiency in Africa by resistance to severe malaria, Nature 376(6537) (1995) 246-9.

[65] A. Manjurano, N. Sepulveda, B. Nadjm, G. Mtove, H. Wangai, C. Maxwell, R. Olomi, H. Reyburn, E.M. Riley, C.J. Drakeley, T.G. Clark, African glucose-6-phosphate dehydrogenase alleles associated with protection from severe malaria in heterozygous females in Tanzania, PLoS Genet 11(2) (2015) e1004960.

[66] G.H. Jacobs, A perspective on color vision in platyrrhine monkeys, Vision research 38(21) (1998) 3307-13.

[67] H. Wu, J. Luo, H. Yu, A. Rattner, A. Mo, Y. Wang, P.M. Smallwood, B. Erlanger, S.J. Wheelan, J. Nathans, Cellular resolution maps of $X$ chromosome inactivation: implications for neural development, function, and disease, Neuron 81(1) (2014) 103-19.

[68] F. Wang, A. Nemes, M. Mendelsohn, R. Axel, Odorant receptors govern the formation of a precise topographic map, Cell 93(1) (1998) 47-60.

[69] D. Kostadinov, J.R. Sanes, Protocadherin-dependent dendritic self-avoidance regulates neural connectivity and circuit function, eLife 4 (2015).

[70] K.R. Johnson, S.A. Cook, L.C. Erway, A.N. Matthews, L.P. Sanford, N.E. Paradies, R.A. Friedman, Inner ear and kidney anomalies caused by IAP insertion in an intron of the Eya1 gene in a mouse model of BOR syndrome, Hum Mol Genet 8(4) (1999) 645-53.

[71] T. Schimmang, Transcription factors that control inner ear development and their potential for transdifferentiation and reprogramming, Hearing research 297 (2013) 84-90. 
[72] H. Niu, L. Makmura, T. Shen, S.S. Sheth, K. Blair, R.A. Friedman, Identification of two major loci that suppress hearing loss and cochlear dysmorphogenesis in Eya1bor/bor mice, Genomics 88(3) (2006) 302-8.

[73] D. Zou, C. Erickson, E.H. Kim, D. Jin, B. Fritzsch, P.X. Xu, Eya1 gene dosage critically affects the development of sensory epithelia in the mammalian inner ear, Hum Mol Genet 17(21) (2008) 3340-56.

[74] S. Abdelhak, V. Kalatzis, R. Heilig, S. Compain, D. Samson, C. Vincent, D. Weil, C. Cruaud, I. Sahly, M. Leibovici, M. Bitner-Glindzicz, M. Francis, D. Lacombe, J. Vigneron, R. Charachon, K. Boven, P. Bedbeder, N. Van Regemorter, J. Weissenbach, C. Petit, A human homologue of the Drosophila eyes absent gene underlies branchio-oto-renal (BOR) syndrome and identifies a novel gene family, Nat Genet 15(2) (1997) 157-64.

[75] V.G. Dantas, E.L. Freitas, V.A. Della-Rosa, K. Lezirovitz, A.M. de Moraes, S.B. Ramos, J. Oiticica, L.U. Alves, P.L. Pearson, C. Rosenberg, R.C. Mingroni-Netto, Novel partial duplication of EYA1 causes branchiootic syndrome in a large Brazilian family, International journal of audiology 54(9) (2015) 593-8.

[76] N. Rydz, J. Leggo, S. Tinlin, P. James, D. Lillicrap, The Canadian "National Program for hemophilia mutation testing" database: a ten-year review, American journal of hematology $88(12)$ (2013) 1030-4.

[77] I. Wieland, S. Jakubiczka, P. Muschke, M. Cohen, H. Thiele, K.L. Gerlach, R.H. Adams, P. Wieacker, Mutations of the ephrin-B1 gene cause craniofrontonasal syndrome, Am J Hum Genet 74(6) (2004) 1209-15.

[78] X. Nan, P. Tate, E. Li, A. Bird, DNA methylation specifies chromosomal localization of MeCP2, Mol Cell Biol 16(1) (1996) 414-21.

[79] R.E. Amir, I.B. Van den Veyver, M. Wan, C.Q. Tran, U. Francke, H.Y. Zoghbi, Rett syndrome is caused by mutations in X-linked MECP2, encoding methyl-CpG-binding protein 2, Nat Genet 23(2) (1999) 185-8.

[80] M.D. Shahbazian, H.Y. Zoghbi, Molecular genetics of Rett syndrome and clinical spectrum of MECP2 mutations, Current opinion in neurology 14(2) (2001) 171-6.

[81] H. Van Esch, M. Bauters, J. Ignatius, M. Jansen, M. Raynaud, K. Hollanders, D. Lugtenberg, T. Bienvenu, L.R. Jensen, J. Gecz, C. Moraine, P. Marynen, J.P. Fryns, G. Froyen, Duplication of the MECP2 region is a frequent cause of severe mental retardation and progressive neurological symptoms in males, Am J Hum Genet 77(3) (2005) 442-53.

[82] U. Grasshoff, M. Bonin, I. Goehring, A. Ekici, A. Dufke, K. Cremer, N. Wagner, E. Rossier, A. Jauch, M. Walter, C. Bauer, P. Bauer, K. Horber, S. Beck-Woedl, D. Wieczorek, De novo MECP2 duplication in two females with random $\mathrm{X}$-inactivation and moderate mental retardation, European journal of human genetics : EJHG 19(5) (2011) 507-12.

[83] J. Menasha, B. Levy, K. Hirschhorn, N.B. Kardon, Incidence and spectrum of chromosome abnormalities in spontaneous abortions: new insights from a 12-year study, Genet Med 7(4) (2005) 251-63.

[84] A.M. Veerappa, P. Padakannaya, N.B. Ramachandra, Copy number variation-based polymorphism in a new pseudoautosomal region 3 (PAR3) of a human X-chromosome-transposed region (XTR) in the Y chromosome, Functional \& integrative genomics 13(3) (2013) 285-93.

[85] S. Benito-Sanz, N.S. Thomas, C. Huber, D. Gorbenko del Blanco, M. Aza-Carmona, J.A. Crolla, V. Maloney, G. Rappold, J. Argente, A. Campos-Barros, V. Cormier-Daire, K.E. Heath, A novel class of Pseudoautosomal region 1 deletions downstream of SHOX is associated with Leri-Weill dyschondrosteosis, Am J Hum Genet 77(4) (2005) 533-44.

[86] S. Jamain, H. Quach, C. Betancur, M. Rastam, C. Colineaux, I.C. Gillberg, H. Soderstrom, B. Giros, M. Leboyer, C. Gillberg, T. Bourgeron, Mutations of the X-linked genes encoding neuroligins NLGN3 and NLGN4 are associated with autism, Nat Genet 34(1) (2003) 27-9.

[87] O. Aseem, J.L. Barth, S.C. Klatt, B.T. Smith, W.S. Argraves, Cubilin expression is monoallelic and epigenetically augmented via PPARs, BMC genomics 14 (2013) 405.

[88] A. Rovelet-Lecrux, D. Hannequin, G. Raux, N. Le Meur, A. Laquerriere, A. Vital, C. Dumanchin, S. Feuillette, A. Brice, M. Vercelletto, F. Dubas, T. Frebourg, D. Campion, APP locus duplication causes autosomal dominant early-onset Alzheimer disease with cerebral amyloid angiopathy, Nat Genet 38(1) (2006) 24-6.

[89] A.B. Singleton, M. Farrer, J. Johnson, A. Singleton, S. Hague, J. Kachergus, M. Hulihan, T. Peuralinna, A. Dutra, R. Nussbaum, S. Lincoln, A. Crawley, M. Hanson, D. Maraganore, C. Adler, M.R. Cookson, M. Muenter, M. Baptista, D. Miller, J. Blancato, J. Hardy, K. Gwinn-Hardy, alphaSynuclein locus triplication causes Parkinson's disease, Science 302(5646) (2003) 841.

[90] J.V. Sanchez-Mut, J. Graff, Epigenetic Alterations in Alzheimer's Disease, Frontiers in behavioral neuroscience 9 (2015) 347. 
[91] P.X. Xu, J. Adams, H. Peters, M.C. Brown, S. Heaney, R. Maas, Eya1-deficient mice lack ears and kidneys and show abnormal apoptosis of organ primordia, Nat Genet 23(1) (1999) 113-7.

[92] E. Ben-David, S. Shohat, S. Shifman, Allelic expression analysis in the brain suggests a role for heterogeneous insults affecting epigenetic processes in autism spectrum disorders, Hum Mol Genet 23(15) (2014) 4111-24.

[93] L. Van Laer, E.H. Huizing, M. Verstreken, D. van Zuijlen, J.G. Wauters, P.J. Bossuyt, P. Van de Heyning, W.T. McGuirt, R.J. Smith, P.J. Willems, P.K. Legan, G.P. Richardson, G. Van Camp, Nonsyndromic hearing impairment is associated with a mutation in DFNA5, Nat Genet 20(2) (1998) 194-7.

[94] S. Kumar, K. Deffenbacher, C.W. Cremers, G. Van Camp, W.J. Kimberling, Branchio-oto-renal syndrome: identification of novel mutations, molecular characterization, mutation distribution, and prospects for genetic testing, Genetic testing 1(4) (1997) 243-51.

[95] S. Wayne, N.G. Robertson, F. DeClau, N. Chen, K. Verhoeven, S. Prasad, L. Tranebjarg, C.C. Morton, A.F. Ryan, G. Van Camp, R.J. Smith, Mutations in the transcriptional activator EYA4 cause late-onset deafness at the DFNA10 locus, Hum Mol Genet 10(3) (2001) 195-200.

[96] S. Melchionda, N. Ahituv, L. Bisceglia, T. Sobe, F. Glaser, R. Rabionet, M.L. Arbones, A. Notarangelo, E. Di lorio, M. Carella, L. Zelante, X. Estivill, K.B. Avraham, P. Gasparini, MYO6, the human homologue of the gene responsible for deafness in Snell's waltzer mice, is mutated in autosomal dominant nonsyndromic hearing loss, Am J Hum Genet 69(3) (2001) 635-40.

[97] R.G. Ruf, P.X. Xu, D. Silvius, E.A. Otto, F. Beekmann, U.T. Muerb, S. Kumar, T.J. Neuhaus, M.J. Kemper, R.M. Raymond, Jr., P.D. Brophy, J. Berkman, M. Gattas, V. Hyland, E.M. Ruf, C. Schwartz, E.H. Chang, R.J. Smith, C.A. Stratakis, D. Weil, C. Petit, F. Hildebrandt, SIX1 mutations cause branchio-oto-renal syndrome by disruption of EYA1-SIX1-DNA complexes, Proc Natl Acad Sci U S A 101(21) (2004) 8090-5.

[98] D. Selcen, F. Muntoni, B.K. Burton, E. Pegoraro, C. Sewry, A.V. Bite, A.G. Engel, Mutation in BAG3 causes severe dominant childhood muscular dystrophy, Annals of neurology 65(1) (2009) 83-9.

[99] R. Ghaoui, J. Palmio, J. Brewer, M. Lek, M. Needham, A. Evila, P. Hackman, P.H. Jonson, S. Penttila, A. Vihola, S. Huovinen, M. Lindfors, R.L. Davis, L. Waddell, S. Kaur, C. Yiannikas, K. North, N. Clarke, D.G. MacArthur, C.M. Sue, B. Udd, Mutations in HSPB8 causing a new phenotype of distal myopathy and motor neuropathy, Neurology 86(4) (2016) 391-8.

[100] B. Gerull, M. Gramlich, J. Atherton, M. McNabb, K. Trombitas, S. Sasse-Klaassen, J.G. Seidman, C. Seidman, H. Granzier, S. Labeit, M. Frenneaux, L. Thierfelder, Mutations of TTN, encoding the giant muscle filament titin, cause familial dilated cardiomyopathy, Nat Genet 30(2) (2002) 201-4.

[101] A. Vincent, N. Forster, J.T. Maynes, T.A. Paton, G. Billingsley, N.M. Roslin, A. Ali, J. Sutherland, T. Wright, C.A. Westall, A.D. Paterson, C.R. Marshall, E. Heon, OTX2 mutations cause autosomal dominant pattern dystrophy of the retinal pigment epithelium, J Med Genet 51(12) (2014) 797-805.

[102] L.M. Zwemer, A. Zak, B.R. Thompson, A. Kirby, M.J. Daly, A. Chess, A.A. Gimelbrant, Autosomal monoallelic expression in the mouse, Genome Biol 13(2) (2012) R10.

[103] I.J. Arnhold, M.M. Franca, L.R. Carvalho, B.B. Mendonca, A.A. Jorge, Role of GLI2 in hypopituitarism phenotype, Journal of molecular endocrinology 54(3) (2015) R141-50.

[104] W.A. Paznekas, B. Karczeski, S. Vermeer, R.B. Lowry, M. Delatycki, F. Laurence, P.A. Koivisto, L. Van Maldergem, S.A. Boyadjiev, J.N. Bodurtha, E.W. Jabs, GJA1 mutations, variants, and connexin 43 dysfunction as it relates to the oculodentodigital dysplasia phenotype, Human mutation 30(5) (2009) 724-33.

[105] G.D. Schellenberg, T.D. Bird, E.M. Wijsman, D.K. Moore, G.M. Martin, The genetics of Alzheimer's disease, Biomedicine \& pharmacotherapy = Biomedecine \& pharmacotherapie 43(7) (1989) 463-8.

[106] M.H. Polymeropoulos, C. Lavedan, E. Leroy, S.E. Ide, A. Dehejia, A. Dutra, B. Pike, H. Root, J. Rubenstein, R. Boyer, E.S. Stenroos, S. Chandrasekharappa, A. Athanassiadou, T. Papapetropoulos, W.G. Johnson, A.M. Lazzarini, R.C. Duvoisin, G. Di lorio, L.I. Golbe, R.L. Nussbaum, Mutation in the alpha-synuclein gene identified in families with Parkinson's disease, Science 276(5321) (1997) 20457.

[107] C.S. Lai, S.E. Fisher, J.A. Hurst, F. Vargha-Khadem, A.P. Monaco, A forkhead-domain gene is mutated in a severe speech and language disorder, Nature 413(6855) (2001) 519-23. 


\begin{tabular}{|c|c|c|c|}
\hline $\begin{array}{l}\text { RME } \\
\text { gene }\end{array}$ & Reference & Autosomal dominant disease & Reference \\
\hline Dfna5 & [12] & \multirow{5}{*}{ Deafness } & [93] \\
\hline Eya1 & [11] & & [94] \\
\hline Eya4 & [11] & & [95] \\
\hline MYO6 & [30] & & [96] \\
\hline Six1 & [11] & & [97] \\
\hline Bag3 & {$[11,12]$} & \multirow{3}{*}{ Myopathies } & [98] \\
\hline Hspb8 & [11] & & [99] \\
\hline TTN & [39] & & [100] \\
\hline OTX2 & [39] & Dystrophy of the retinal pigment epithelium & [101] \\
\hline Gli2 & [102] & Hypopituitarism & [103] \\
\hline Gja1 & [10] & Oculodentodigital dysplasia & [104] \\
\hline APP & [30] & \multirow{2}{*}{ Neurodegenerative diseases } & [105] \\
\hline SNCA & {$[11,30]$} & & [106] \\
\hline FOXP2 & [28] & Speech and language disorder & [107] \\
\hline
\end{tabular}

Table 1 - Potential implications of random monoallelic expression (RME) for pathologies.

The table shows examples of autosomal genes identified as random monoallelically expressed in clonal cell populations in independent studies (columns $1 \& 2$ ) and associated with human autosomal dominant disorders (columns $3 \& 4$ ).

\section{Figure legends}

Figure 1- Schematic representation of different types of random monoallelic expression that arise during development. Random X-chromosome inactivation $(\mathrm{XCl})$ and autosomal random monoallelic expression (RME) are stable and clonally inherited, as opposed to dynamic allelic expression.

Figure 2- Schematic representations of the potential mechanisms underlying establishment and/or maintenance of autosomal random monoallelic expression (RME) patterns.

Figure 3- Schematic view of the potential role of random monoallelic expression (RME) in the generation of cellular diversity. 
Figure 1
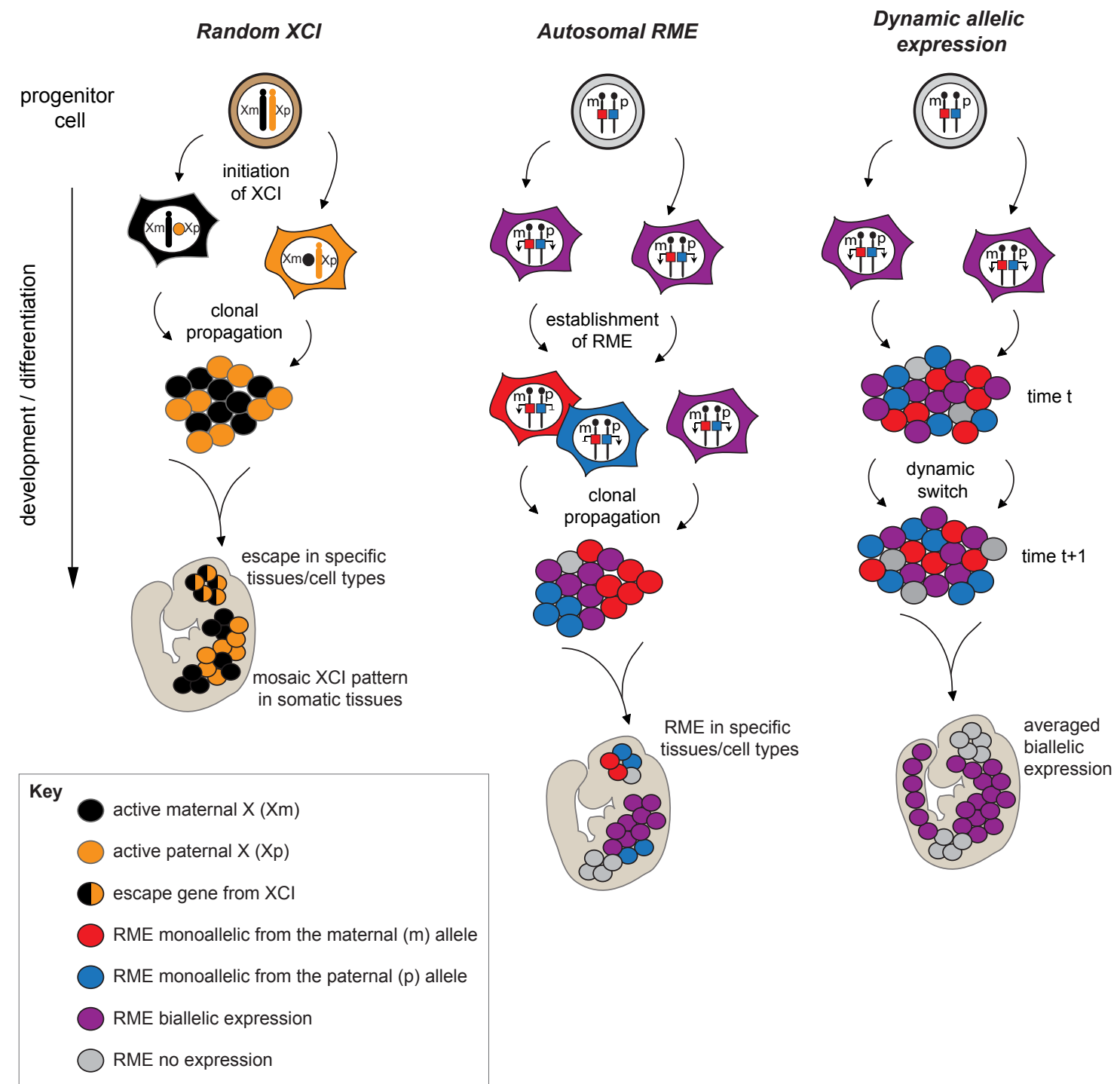
Figure 2

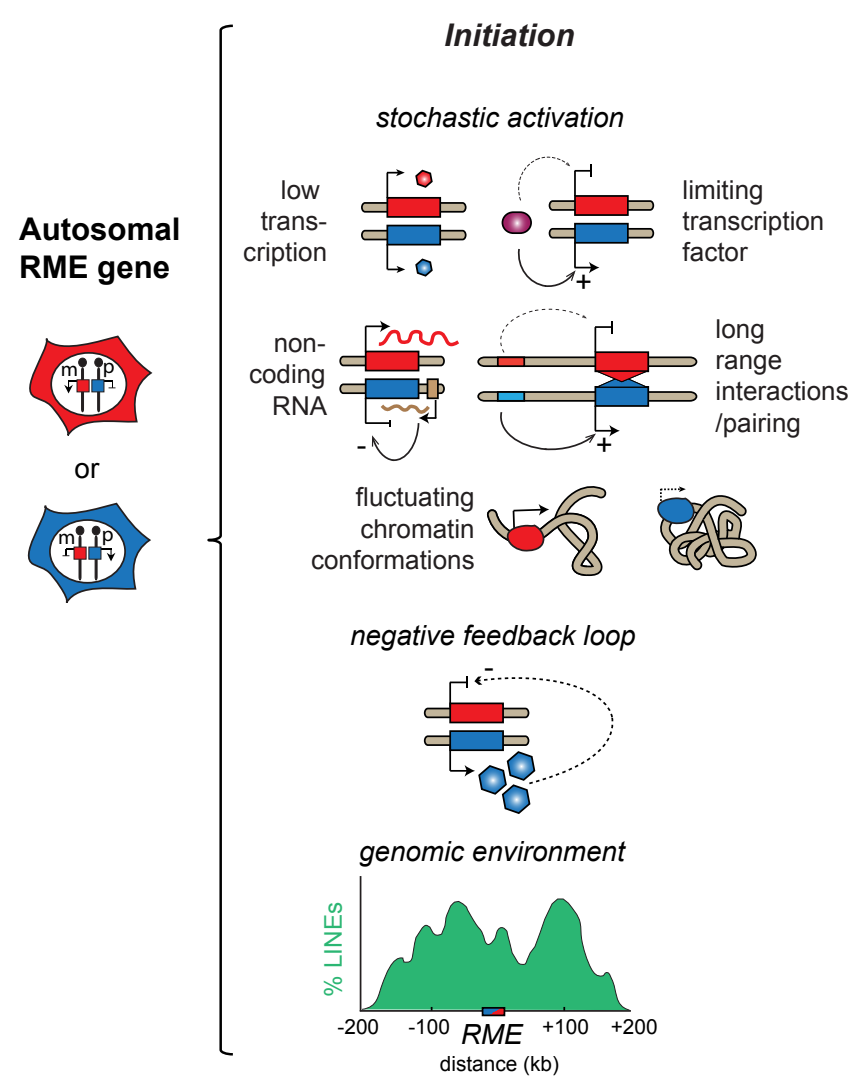

Initiation

/ maintenance

nuclear positioning

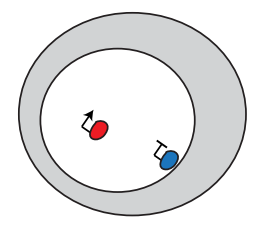

asynchronous replication

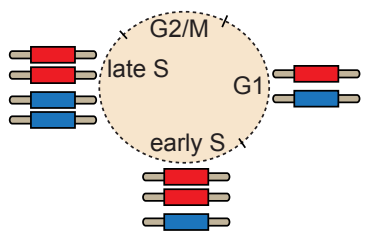

Maintenance

DNA methylation

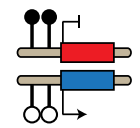

histone modifications (promoter/gene body)

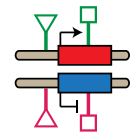


Figure 3

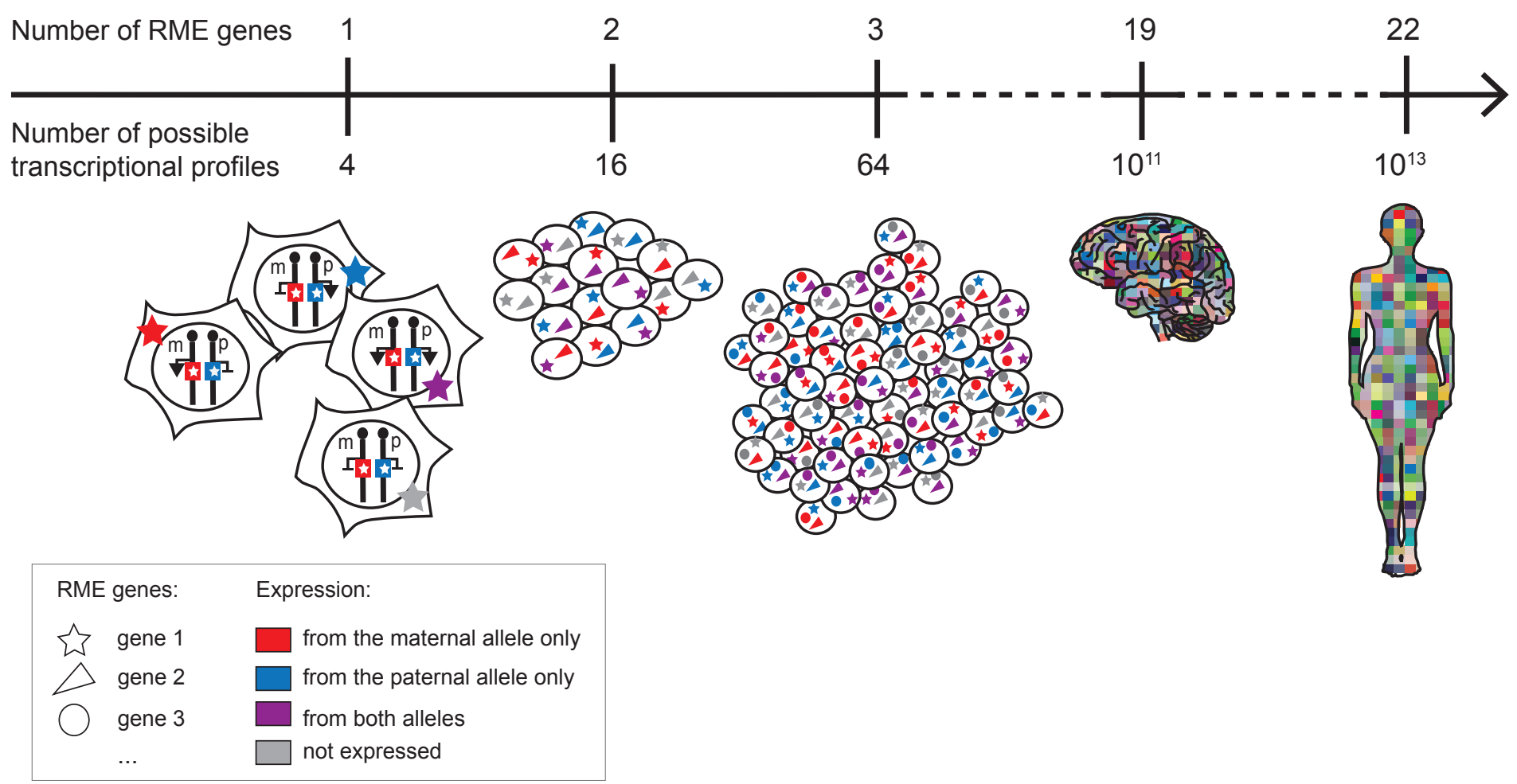

